\title{
Abatement of an Azo Dye on Structured C-Nafion/Fe-Ion Surfaces by Photo-Fenton Reactions Leading to Carboxylate Intermediates with a Remarkable Biodegradability Increase of the Treated Solution
}

\author{
S. Parra, ${ }^{\dagger}$ I. Guasaquillo, ${ }^{\dagger}$ O. Enea,$\stackrel{\dagger}{\ddagger}$. Mielczarski, ${ }^{\S}$ J. Mielczarki, ${ }^{\S}$ P. Albers,${ }^{\perp}$ \\ L. Kiwi-Minsker," and J. Kiwi*,† \\ Laboratory of Photonics and Interfaces, Institute of Molecular Chemistry and Biology, \\ Swiss Federal Institute of Technology, Lausanne 1015, Switzerland, UMR 6503 CNRS, \\ University of Poitiers, 86022 Poitiers Cedex, France, Laboratory LEM/UMR 7569, CNRS INPL-ENSG, \\ 5401 Vandoeuvre les Nancy Cedex, France, Infracor GmbH, ATS-PCP, D-63403 Hanau/Main, Germany, \\ Laboratory of Chemical Reaction Engineering, Institute of Chemical and Biological Processes, \\ Swiss Federal Institute of Technology, Lausanne 1015, Switzerland
}

Received: January 15, 2003; In Final Form: April 21, 2003

\begin{abstract}
A novel C-Nafion/Fe-ion structured fabric capable of mediating Orange II decomposition in Fenton-immobilized photoassisted reactions is presented. The catalyst preparation requires the right balance between the amount of the Nafion necessary to protect the C-surface and the minimum encapsulation of the Fe-cluster catalytic sites inside the Nafion to allow the photocatalysis to proceed. The C-Nafion/Fe fabric can be used up to $\mathrm{pH}$ 10 under light to photocatalyze the disappearance of Orange II in the presence of $\mathrm{H}_{2} \mathrm{O}_{2}$. The photocatalysis mediated by the C-Nafion/Fe-ion fabric increased with the applied light intensity and reaction temperature in the reaction needing an activation energy of $9.8 \mathrm{kcal} / \mathrm{mol}$. This indicates that ion - and radical-molecule reactions take place during Orange II disappearance. The build up and decomposition of intermediate iron complexes under light involves the recycling of $\mathrm{Fe}^{2+}$ and was detected by infrared spectroscopy (FTIR). This observation, along with other experimental results, allows us to suggest a surface mechanism for the dye degradation on the $\mathrm{C}$-Nafion/Fe-ion fabrics. The C-Nafion/Fe-ion fabric in the presence of $\mathrm{H}_{2} \mathrm{O}_{2}$ under solar simulated light transforms the totally nonbiodegradable Orange II into a biocompatible material with a very high $\mathrm{BOD}_{5} / \mathrm{COD}$ value. X-ray photoelectron spectroscopy (XPS) and sputtering by $\mathrm{Ar}^{+}$-ions of the upper surface layer of the $\mathrm{C}$-Nafion/Fe-ion fabric allow us to describe the intervention of the photocatalyst down to the molecular level. Most of the Fe clusters examined by transmission electron microscopy (TEM) showed particle sizes close to $4 \mathrm{~nm}$ due to their encapsulation into the Gierke cages of the Nafion thin film observed by scanning electron microscopy (SEM) and optical microscopy (OM).
\end{abstract}

\section{Introduction}

The photo-Fenton reagent $\left(\mathrm{Fe}^{3+} / \mathrm{Fe}^{2+} / \mathrm{H}_{2} \mathrm{O}_{2}\right)$ is an efficient and cheap reagent to generate oxidative radicals such as $\mathrm{OH}^{\bullet}$ and $\mathrm{HO}_{2}{ }^{\bullet}$ in homogeneous reactions, ${ }^{1}$ capable of oxidizing organic compounds to $\mathrm{CO}_{2}$ and water. Iron in its ferrous and ferric form acts as a photocatalyst and requires a working $\mathrm{pH}$ $\leq 4$. At higher $\mathrm{pH}$ values, iron precipitates as a hydroxide. The reversible iron cycle during a photoassisted Fenton homogeneous reaction involves the first step $^{2}$

$$
\mathrm{H}_{2} \mathrm{O}_{2}+\mathrm{Fe}^{2+} \rightarrow \mathrm{Fe}^{3+}+\mathrm{HO}^{-}+\mathrm{HO}^{\bullet} \quad k_{1}=40-60 \mathrm{M}^{-1} \mathrm{~s}^{-1}
$$

In the second step, $\mathrm{Fe}^{3+}$-ions are reduced by light ${ }^{2}(\lambda<330$ $\mathrm{nm}$ ), which generates additional $\mathrm{OH}^{\bullet}$ radicals

$$
\mathrm{Fe}(\mathrm{OH})^{2+} \stackrel{h v}{\longrightarrow} \mathrm{Fe}^{2+}+\mathrm{HO}^{\bullet} \quad k_{2}=2 \times 10^{-3} \mathrm{M}^{-1} \mathrm{~s}^{-1}
$$

\footnotetext{
$\dagger$ Institute of Molecular Chemistry and Biology, Swiss Federal Institute of Technology.

$\stackrel{+}{\dagger}$ University of Poitiers.

$\S$ CNRS INPL-ENSG.

$\perp$ Infracor $\mathrm{GmbH}$.

"Institute of Chemical and Biological Processes, Swiss Federal Institute of Technology.
}

The ligand to metal charge transfer (LMCT) via a complex with carboxylate radicals ${ }^{3}$ takes place in a redox photo-Kolbe process leading to decarboxylation of the organic compound

$$
[\mathrm{RCOO}-\mathrm{Fe}]^{2+} \rightarrow\left[\mathrm{R}^{\bullet}\right]+\mathrm{CO}_{2}+\mathrm{Fe}^{2+}
$$

During the homogeneous Fenton reactions, the $\mathrm{pH}$ has to be adjusted twice, first to an acidic $\mathrm{pH}<4$ to carry out the Fenton pretreatment and then back to a neutral $\mathrm{pH}$. In this way, it is possible to proceed with the lower cost second stage biological destruction of the organic compound(s) once the biocompatibility has been attained during the Fenton pretreatment. This is why supported Fenton-immobilized catalysts have been recently developed to overcome the costly $\mathrm{pH}$ adjustment on Nafion membranes, ${ }^{2}$ silica structured surfaces, ${ }^{3}$ Nafion silica surfaces ${ }^{4}$ polyethylene copolymers,${ }^{5}$ and alginate microcapsules. ${ }^{6}$ These supported catalysts have been developed during the past few years with the intention of (a) withstanding the corrosion due to the oxidative radicals produced in solution, (b) fixing the Fe-ions on a support in a stable way so as not to allow them to leach out during the reaction, and (c) allowing the Fenton-mediated catalysis to proceed at acceptable kinetic rates.

Recently oven fibrous materials have become important as structured catalytic beds for reactor processes. ${ }^{3}$ C-fibers and 
fabrics have been used recently for metal deposition and tested as catalysts in a variety of processes. ${ }^{7,8}$ These materials are bidimensional and possess adequate mechanical and thermal resistance. The functional groups on $\mathrm{C}$-fabrics can exchange extensively and retain strongly the Fe species necessary for the Fenton catalysis involving decomposition of $\mathrm{H}_{2} \mathrm{O}_{2}$.

In the present study, we present a $\mathrm{C}-\mathrm{Nafion} / \mathrm{Fe}$-ion fabric as a composite material being applied for the first time as a stable immobilized catalyst decomposing Orange II by Fenton photoassisted reactions. A novel composite catalyst consisting of C-filaments of $7 \mu \mathrm{m}$ aligned in a woven structure covered by a Nafion film on which Fe-ions have been exchanged is studied in detail. The $\mathrm{C}$-fabric presented in this study shows adequate characteristics during the oxidative Fenton processes when used in photoreactors with suitable dimensions and geometry for the objective of this study. The results presented show the photocatalytic decomposition of the model azo dye compound, the activation energy $\left(E_{\mathrm{a}}\right)$ of the process, the modeling of the reaction kinetics taking place in the cylindrical reactor, and the remarkable increase in the biodegradability of the pretreated solutions.

The C-structured loaded and unloaded surface characterization was carried out by electron microscopy (optical, SEM, and TEM), surface area measurements (BET), electrical resistance of the surface, photoelectron spectroscopy (XPS), and external reflection Fourier-transform infrared spectroscopy (ERFTIR) to determine the catalyst morphology and the surface composition at the molecular levels.

\section{Experimental Section}

Chemicals and Fabrics. Nafion perfluorinated ion-exchange resin $5 \%$ by weight solution in methanol (Aldrich 51, 921-1) was used as received. Acids and bases, methanol, $\mathrm{Fe}_{2}\left(\mathrm{SO}_{4}\right)_{3}$. $7 \mathrm{H}_{2} \mathrm{O}, \mathrm{KSCN}$, Orange II, and $\mathrm{H}_{2} \mathrm{O}_{2}$ were p.a. Fluka $\mathrm{AG}$ products (Buchs, Switzerland) and used as received.

The C-fabrics were received from Longfellow Cambridge Ltd, Cambridge, U.K. After preliminary screening, a C-fabric 400 Tex with 6000 filaments/fiber of $7 \mu \mathrm{m}$ each was chosen and used throughout this study on the basis of the favorable disappearance rate of Orange II. This C-fabric 400 Tex was $0.4 \mathrm{~mm}$ thick and $406 \mathrm{~g} / \mathrm{m}^{2}$ in weight and had a negligible surface area of $0.33 \mathrm{~m}^{2} / \mathrm{g}$. Other C-fabrics screened were 66 Tex and 200 Tex having 1000 and $3000 \mathrm{C}$-filaments/fiber. The reasons for the better performance of the $\mathrm{C}$-fabric $400 \mathrm{Tex}$ with regards to the 66 and 200 Tex C-fabrics will be dealt with in the Results and Discussion section. The C-fabrics used were all stable in air and room temperature. The electrical resistance found for the C-fabrics 66, 200, and 400 Tex were 8, 25, and $50 \Omega / \mathrm{cm}$, respectively.

Preparation of C-Nafion/Fe-Ion Fabrics. The C-fabrics were cleaned with adequate amounts of methanol, immersed in the 5\% Nafion solution, dried, washed with acid and $\mathrm{H}_{2} \mathrm{O}_{2}$, and subsequently exchanged with $\mathrm{Fe}_{2}\left(\mathrm{SO}_{4}\right)_{3} \cdot 7 \mathrm{H}_{2} \mathrm{O}$. Finally, the $\mathrm{C}$-Nafion/Fe-ion fabrics were washed with an abundant amount of distilled water and dried.

During the preparation of the membranes, the question of how many layers of Nafion were necessary to attain the most suitable photocatalytic disappearance of Orange II by the $\mathrm{C}-\mathrm{Nafion} / \mathrm{Fe}$-ion fabric was investigated in a systematic way. It was found that one Nafion protective layer on the C-fabric was not enough. When two layers of Nafion were applied on the $\mathrm{C}$-fabric, the performance of the $\mathrm{C}$-Nafion fabric after $\mathrm{Fe}$ exchange was still not reproducible. But when three layers of Nafion were applied, the results with the C-Nafion/Fe-ion fabric showed optimal Orange II decoloration kinetics. When four
Nafion layers were applied prior to the Fe-exchange, the photocatalytically mediated disappearance of Orange II required much longer times. These less favorable decoloration kinetics were probably due to a thicker Nafion coating encapsulating the Fe-ions. With three Nafion coatings on the C-fabric the reproducibility found for the decoloration of Orange II was on the order of $\pm 5 \%$. This shows the validity of the preparative method used for the C-Nafion/Fe-ion fabrics used throughout this study.

Photoreactor and Irradiation Procedures. The photocatalytic activity of the structured $\mathrm{C}$-Nafion/Fe-ion fabric was evaluated in $70 \mathrm{~mL}$ cylindrical reaction vessels. The light source was a Suntest solar simulator. The Suntest lamp had a wavelength distribution with about $7 \%$ of the photons between 290 and $400 \mathrm{~nm}$. The emission profile of the photons between 400 and $800 \mathrm{~nm}$ followed the solar spectrum. The radiant flux of the Suntest light was measured with a power meter from LSI Corp., Yellow Springs, CO. The C-Nafion/Fe-ion fabric was located right behind the reactor wall. The $\mathrm{H}_{2} \mathrm{O}_{2}$ was added at the beginning of each run in the required amounts.

Chemical Oxygen Demand (COD). The measurement was carried out on a Hach DR/2000 optical unit. Test solutions (2 $\mathrm{mL}$ ) were pipetted into a dichromate solution and digested at $150{ }^{\circ} \mathrm{C}$ for $2 \mathrm{~h}$. The optical density for the change in color of the dichromate solution was determined at $\lambda=430 \mathrm{~nm}$.

Biological Oxygen Demand (BOD). This test was carried out by means of a BOD controller model 1020 (WTW). The unit was thermostated at $20^{\circ} \mathrm{C}$. The $\mathrm{pH}$ of the samples was adjusted between 6.8 and 7.5 before an addition $(10 \% \mathrm{v} / \mathrm{v})$ of decanted sludge (inoculum from the biological treating station of Vidy, Lausanne) in the presence of the nutrients necessary for the bacterial activity.

Analysis of the Irradiated Solutions. Spectrophotometric analyses of the solutions were carried out using of a HewlettPackard 8452 diode-array spectrophotometer. The total organic carbon (TOC) was monitored via a Shimadzu 500 instrument equipped with an ASI automatic sample injector. The peroxide concentrations were assessed using Merkoquant paper and found to be at levels between 0.5 and $25 \mathrm{mg} / \mathrm{L}$ of $\mathrm{H}_{2} \mathrm{O}_{2}$. The dye disappearance was monitored by a Varian HPLC provided with a 9065 diode. A Phenomenex C-18 inverse phase column was used, and the dye signals were recorded at 229 and $254 \mathrm{~nm}$. The gradient solution used was regulated with a buffer consisting of ammonium acetate and methanol.

Fourier-Transform Infrared Spectroscopy. The detailed description of the applied external reflection FTIR technique and procedure used has been previously reported. ${ }^{9}$ The infrared reflection spectra of catalyst samples were recorded on a Bruker IFS55 FTIR spectrometer equipped with an MCT detector and a reflection attachment (Seagull). A wire-grid polarizer was placed before the sample and provided p- or s-polarized light. These accessories were from Harrick Scientific Co. It was found for the system under investigation that the most informative reflection spectra could be recorded by the use of p-polarized light and an angle of incidence of $20^{\circ}$. The unit of intensity was defined as $-\log \left(R / R_{0}\right)$, where $R_{0}$ and $R$ are the reflectivities of the catalyst sample after the reaction and before the reaction directly after its preparation, respectively. Both sample and reference spectra are averaged over the same number of 1000 scans.

X-ray Photoelectron Spectroscopy (XPS). Measurements were carried out in a Leybold-Heraeus instrument calibrating the binding energies (BE) to the $\mathrm{Au} \mathrm{f}_{7 / 2}$ level taken as $84.0 \mathrm{eV}$. The evaluation of the binding energies of the embedded $\mathrm{Fe}$ 


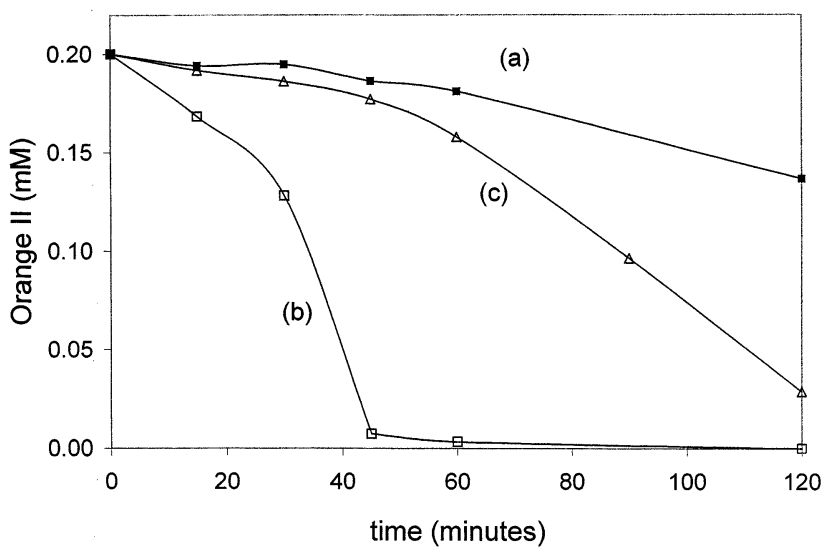

Figure 1. Decoloration of a solution of Orange II $(0.2 \mathrm{mM})$ at an initial $\mathrm{pH} 5.1$ (natural $\mathrm{pH}$ ) in the presence of $\mathrm{H}_{2} \mathrm{O}_{2}(10 \mathrm{mM})$ and (a) dark reaction in the presence of a C-Nafion/Fe-ion fabric, (b) light reaction using a Suntest sunlight simulator $\left(90 \mathrm{~mW} / \mathrm{cm}^{2}\right)$ in the presence of a C-Nafion/Fe-ion fabric, and (c) homogeneous Fenton reaction using a Suntest sunlight simulator $\left(90 \mathrm{~mW} / \mathrm{cm}^{2}\right)$ with $0.5 \mathrm{mg} \mathrm{Fe}$-ion/L. For more details, see text.

clusters was carried out following the DIN norms ${ }^{10}$ and, after the sensitivity factors were taken into consideration, allowed a reproducibility of $\pm 5 \%$ in the measurements. The quantitative evaluation of the experimental data was carried out with a Shirley-type background correction ${ }^{11}$ due to the electrostatic charging of the particles during the measurements. The sputtering of the external surface loaded fabric was carried out with Ar-ions, and after the Ar-ion bombardment, the recorded oxidation states of the surface species may not entirely correspond to the true states in the $\mathrm{C}-\mathrm{Nafion} / \mathrm{Fe}$-ion fabric because the Ar-ion treatment changes the nature of the fabric to some extent.

Optical Microscopy, Transmission Electron Microscopy (TEM), and Scanning Electron Microscopy (SEM). The optical microscope, an Olympus 9M, provided with a digital camera was used to record the images of the $\mathrm{C}$-fabrics and the largest Nafion deposits at enlargements of 24, 40, and 66 times. The scanning electron microscopy (SEM) was performed with a JEOL $35 \mathrm{CF}(15 \mathrm{kV}, 15 \mathrm{~nm}$ point resolution) to observe the C-fabrics covered by some Nafion deposits with a gold layer $0.1 \mathrm{~nm}$ thick. A field emission TEM, the Philips CM 120 microscope, was used to observe the Fe clusters on the Nafion on the C-fabric surface. The C-fabric was coated with epoxy resin, and the fabric was cut with a microtome to a thin layer of $50 \mathrm{~nm}$ at a $90^{\circ}$ angle for the experimental observations. The instrument used for electron microscopy $(120 \mathrm{kV}, 0.35 \mathrm{~nm}$ point resolution) was equipped with an energy-dispersive X-ray analysis EDAX to identify the Fe clusters on the support.

\section{Results and Discussions}

Immobilized C-Nafion/Fe-Ion Fabrics Versus Fenton Homogeneous Photoassisted Decoloration of Orange II. Figure 1 (trace a) shows the lack of decoloration of Orange II in the dark in the presence of a C-Nafion/Fe-ion fabric. Under Suntest light irradiation, Figure 1 (trace b) shows that Orange II is completely decomposed in $\sim 40 \mathrm{~min}$. After a photocatalytic run the amount of $\mathrm{Fe}^{3+}$ was analyzed in solution by complexing the $\mathrm{Fe}^{3+}$ with thiocyanate and found to be always $\leq 0.5 \mathrm{mg} / \mathrm{L}$. To reference the results obtained (trace c), Orange II was run under Suntest irradiation with a solution containing $\mathrm{Fe}^{3+}(0.5$ $\mathrm{mg} / \mathrm{L})$. The results in Figure 1 show that the decoloration of Orange II within $40 \mathrm{~min}$ is mainly due to the C-Nafion/Fe-ion fabric and only to a very small extent to the Fenton homogeneous residual reaction going on in parallel in the reactor.

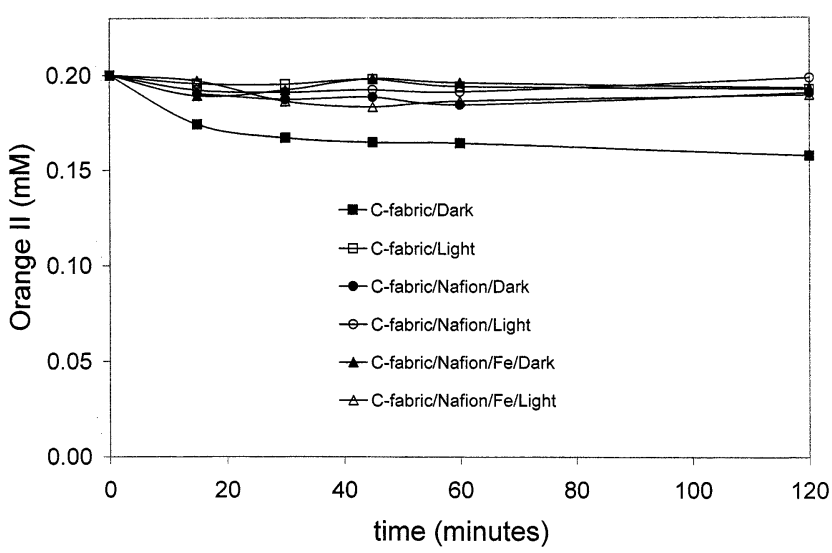

Figure 2. Decoloration of a solution of Orange II $(0.2 \mathrm{mM})$ at an initial $\mathrm{pH} 5.1$ (natural $\mathrm{pH}$ ) under Suntest light irradiation $(90 \mathrm{~mW} /$ $\mathrm{cm}^{2}$ ) and during dark reactions in the absence of $\mathrm{H}_{2} \mathrm{O}_{2}$ on C-fabrics, $\mathrm{C}$-Nafion fabrics, and $\mathrm{C}-\mathrm{Nafion} / \mathrm{Fe}$-ion fabrics. For other details, see the legend.

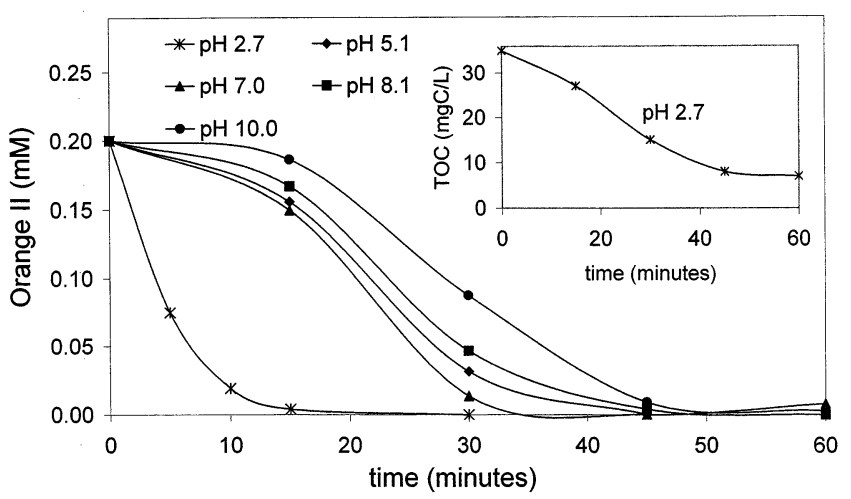

Figure 3. Decoloration of Orange II $(0.2 \mathrm{mM})$ under Suntest light in the presence of $\mathrm{H}_{2} \mathrm{O}_{2}(10 \mathrm{mM})$ mediated by a C-Nafion/Fe-ion fabric as a function of the initial $\mathrm{pH}$ of the solution. The insert shows the total organic carbon (TOC) as a function of time for the initial $\mathrm{pH}$ of 2.7 .

The C-Nafion/Fe-ion fabric used in Figure 1 had an adequate coverage consisting of three Nafion layers on the $\mathrm{C}$-fabric. The Nafion film did not allow a strong encapsulation of the Nafion $\mathrm{Fe}$-ions that would hinder the catalytic decomposition of the $\mathrm{H}_{2} \mathrm{O}_{2}$ in solution by the Fe clusters inside the Gierke cages (see Experimental Section).

Figure 2 shows the practical absence of Orange II decoloration when C-fabrics, C-Nafion fabrics, and C-Nafion/Fe-ion fabrics were used as catalysts in the dark or light-induced processes in the absence of $\mathrm{H}_{2} \mathrm{O}_{2}$. A small decoloration was observed during Orange II decoloration in the dark due to some minor adsorption or interaction between the Orange II and the redox impurities of the C-fabric surface or both. Orange II adsorption was not observed on C-Nafion and C-Nafion/Fe-ion fabrics.

$\mathrm{Up}$ to eight recycles were carried out to test the catalytic nature of the Orange II mediated decoloration by C-Nafion/Feion. The experimental conditions used were the same as those in Figure 1. After each recycling, the fabric was thoroughly washed with distilled water.

Kinetics of Orange II Decomposition as a Function of the Initial $\mathbf{p H}$ and $\mathrm{H}_{2} \mathrm{O}_{2}$ Concentration. Figure 3 shows Orange II disappearance during Suntest irradiation mediated by CNafion/Fe-ion fabrics as a function of the initial $\mathrm{pH}$ of the solution. Slower kinetics for processes at initial $\mathrm{pH}$ values of $10,8.1,7.0$, and 5.1 compared to $\mathrm{pH} 2.7$ is observed. Similar results have been observed before for Orange II degradation in homogeneous photoassisted Fenton reactions. The complex 
shape for the Orange II concentration as a function of time suggests the presence of $\mathrm{pH}$-dependent transient intermediates affecting the course of Orange II disappearance. These solutions did not precipitate, and $\mathrm{Fe}$ aqueous complexes intervening favorably during Orange II disappearance begin to be effective after $\sim 15 \mathrm{~min}$ for Orange II solutions with an initial $\mathrm{pH}>5.1$. The insert in Figure 3 shows the decrease of TOC for Orange II solutions with initial $\mathrm{pH}$ of 2.7. TOC reduction of Orange II solutions was observed only at this low initial $\mathrm{pH}$-value. This implies that intermediates required for a reduction of TOC are only effective at acidic $\mathrm{pH}$ values $\leq 4 .^{2,12,13}$ If we start at higher $\mathrm{pH}$ values, the intermediates produced in solution preclude further degradation of Orange II in solutions with an initial $\mathrm{pH}$ $\geq 5.1$ as seen in Figure 3. The residual TOC noted in the insert of Figure 3 did not decrease with increasing concentration of $\mathrm{H}_{2} \mathrm{O}_{2}$. Because decoloration proceeds well at $\mathrm{pH}$ values up to 10 (Figure 3), the intermediates leading to decoloration are quite different in nature than the ones involved in the TOC reduction during the photocatalysis of Orange II as reflected in the rates

$$
\begin{aligned}
\text { Orange II } \stackrel{k_{4}}{\longrightarrow} \text { organic intermediates } \stackrel{k_{4 \mathrm{a}}}{\longrightarrow} \mathrm{CO}_{2} \\
\text { where } k_{4} \gg k_{4 \mathrm{a}}
\end{aligned}
$$

The $\mathrm{OH}^{\bullet}$ and $\mathrm{HO}_{2}{ }^{\bullet}$ radicals react rapidly and unselectively with aromatic compounds with rate constants of $10^{9}-10^{10} \mathrm{M}^{-1} \mathrm{~s}^{-1}$ and $10^{6}-10^{8} \mathrm{M}^{-1} \mathrm{~s}^{-1}$, respectively. Intermediates produced during Orange II degradation under light irradiation in the presence of $\mathrm{O}_{2}$ and $\mathrm{H}_{2} \mathrm{O}_{2}$ have been reported before, ${ }^{19}$ but the exact nature of their composition in the case of homogeneous Fenton systems is not known. By HPLC, it was not possible to determine these Fe complex intermediates present in solution, and GC-MS work is under way to clear this point. The $\mathrm{pH}$ for Orange II solutions with an initial $\mathrm{pH}$ above 5.1 reaches a $\mathrm{pH}$ of $\sim 4$ after $15 \mathrm{~min}$ of light irradiation. This time period coincides with the start of the decoloration reported for Orange II solutions in Figure 3. Only when the $\mathrm{pH}$ value was close to 4 was the decoloration of Orange II able to proceed as reported in Figure 3. At more basic $\mathrm{pH}$ values, the $\mathrm{Fe}\left(\mathrm{H}_{2} \mathrm{O}\right)_{6}{ }^{3+}$ species $\left(\mathrm{p} K_{\mathrm{a}}=2.8\right)$ deprotonates rapidly to $\mathrm{Fe}\left(\mathrm{H}_{2} \mathrm{O}\right)_{5} \mathrm{OH}^{2+}$ and $\mathrm{Fe}\left(\mathrm{H}_{2} \mathrm{O}\right)_{4} \mathrm{OH}^{+12-15}$ hindering the decoloration of Orange II at reaction times $<15$ min (Figure 3 ). In addition at acidic $\mathrm{pH}$ values, the $\mathrm{OH}^{\bullet}$ radical has been reported to be the dominant species when $\mathrm{Fe}(\mathrm{OH})^{2+}$ is present in solution. ${ }^{16,17}$ Recently, adduct formation between $\mathrm{OH}^{\bullet}$ and Orange II has been reported during Orange II decomposition at acidic $\mathrm{pH}$ values involving protonated species. ${ }^{18,19}$

Figure 4 presents the decoloration kinetics of Orange II as a function of the added concentration of $\mathrm{H}_{2} \mathrm{O}_{2}$. It is readily seen that increasing the amount of $\mathrm{H}_{2} \mathrm{O}_{2}$ leads to a faster Orange II decoloration up to $10 \mathrm{mM}$. Beyond the latter $\mathrm{H}_{2} \mathrm{O}_{2}$ concentration, an increase in the amount of $\mathrm{H}_{2} \mathrm{O}_{2}$ added slows down the decoloration because the propagation step shown in eq 5 is hindered by the excess $\mathrm{H}_{2} \mathrm{O}_{2}$ scavenging the available $\mathrm{OH}^{\bullet}$ radicals

$$
\mathrm{H}_{2} \mathrm{O}_{2}+\mathrm{OH}^{\bullet} \rightarrow \mathrm{H}_{2} \mathrm{O}+\mathrm{HO}_{2}^{\bullet} \quad k_{5}=1.2 \times 10^{7} \mathrm{M}^{-1} \mathrm{~s}^{-1}
$$

Energy of Activation $\left(E_{\mathrm{a}}\right)$ and Light Intensity Dependence of the Orange II Decoloration. Figure 5 shows the decoloration of an Orange II $(0.2 \mathrm{mM})$ solution as a function of the applied temperature that was controlled with a thermostat during the experiment. It is readily seen from Figure 5 that an increase in

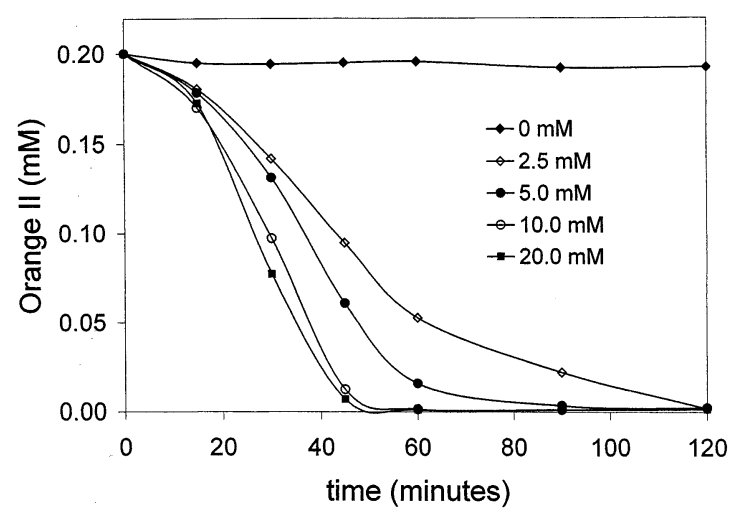

Figure 4. Kinetics of Orange II $(0.2 \mathrm{mM})$ decoloration as a function of added $\mathrm{H}_{2} \mathrm{O}_{2}$ concentration at an initial $\mathrm{pH} 5.1$ in the presence of a $\mathrm{C}-\mathrm{Nafion} / \mathrm{Fe}$-ion fabric under Suntest light irradiation.

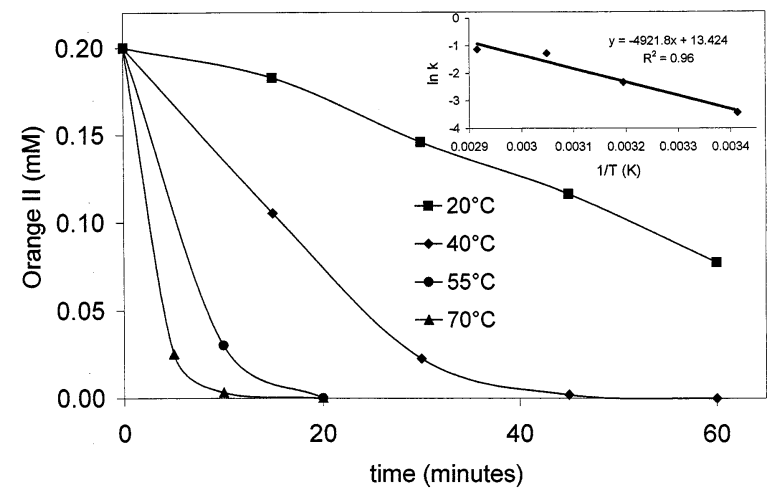

Figure 5. Reduction of the Orange II concentration in a solution containing $\mathrm{H}_{2} \mathrm{O}_{2}(10 \mathrm{mM})$ in the presence of a C-Nafion/Fe-ion fabric under Suntest light as a function of the applied temperature. The insert shows the plot used to obtain the activation energy $\left(E_{\mathrm{a}}\right)$ of Orange II decoloration.

temperature has a beneficial effect on the decoloration rate. The $E_{\mathrm{a}}$ was determined by following the concentration of Orange II at $20,40,55$, and $70{ }^{\circ} \mathrm{C}$ vs time. At each temperature, the initial decrease of the decoloration rate in millimoles per minute was estimated. Only the initial values of the tangent in Figure 5 were taken into account for the calculation of $k$ because of the shapes observed for the decoloration process in Figure 5. In this way, the input due to the light energy is minimized and the temperature effect is considered in Figure 5. A value of 9.8 $\mathrm{kcal} / \mathrm{mol}$ was obtained from the graph of $\ln k$ vs $1 / T \mathrm{~K}$. The latter value suggests that ion-molecule reaction and radicalmolecule reactions requiring some activation energy occur during Orange II disappearance, as well as the radical-radical reactions that need no $E_{\mathrm{a}}$.

Figure 6 shows the dependence of the decoloration on the intensity of the applied light from the Suntest solar simulator. The intensity of $50 \mathrm{~mW} / \mathrm{cm}^{2}$ corresponds to $50 \%$ of the full light intensity of equatorial solar radiation perpendicular to the equator (AM1). Consequently, $90 \mathrm{~mW} / \mathrm{cm}^{2}$ corresponds to $90 \%$ of AM1. Accelerated decoloration was obtained when a medium-pressure mercury arc (Applied Photophysics, U.K.) with the main radiation centered at $366 \mathrm{~nm}$ was used as the radiation source with $6 \times 10^{19}$ photons/s. A quicker decoloration was obtained with $90 \mathrm{~mW} / \mathrm{cm}^{2}$ as compared to a light intensity of $50 \mathrm{~mW} / \mathrm{cm}^{2}$. This implies that there is no saturation of the Orange II solution by the photon density of the applied light. Orange II, being the light absorber under visible irradiation, initiates the decoloration process mediated at a later stage by $\mathrm{C}$-Nafion/Fe-ion fabrics in this dye-sensitized process. ${ }^{13,19}$ 


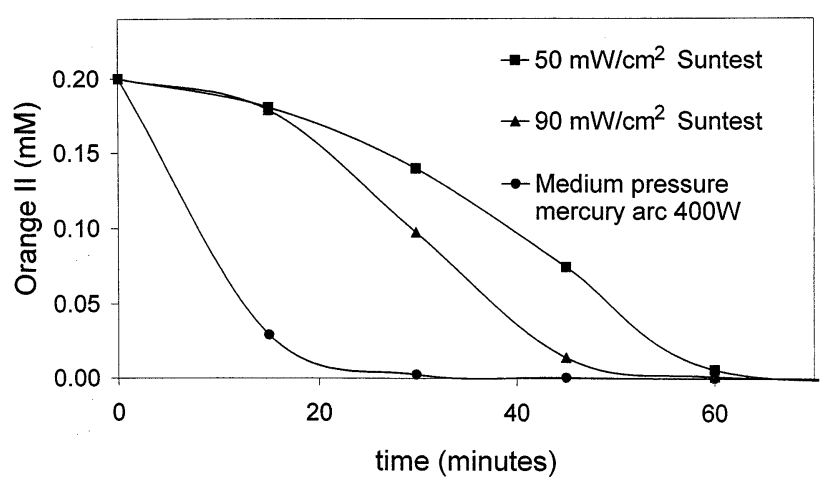

Figure 6. Reduction of the Orange II concentration in a solution containing $\mathrm{H}_{2} \mathrm{O}_{2}(10 \mathrm{mM})$ in the presence of a C-Nafion/Fe-ion fabric as a function of the applied light and intensity of the light used. For other details, see text.

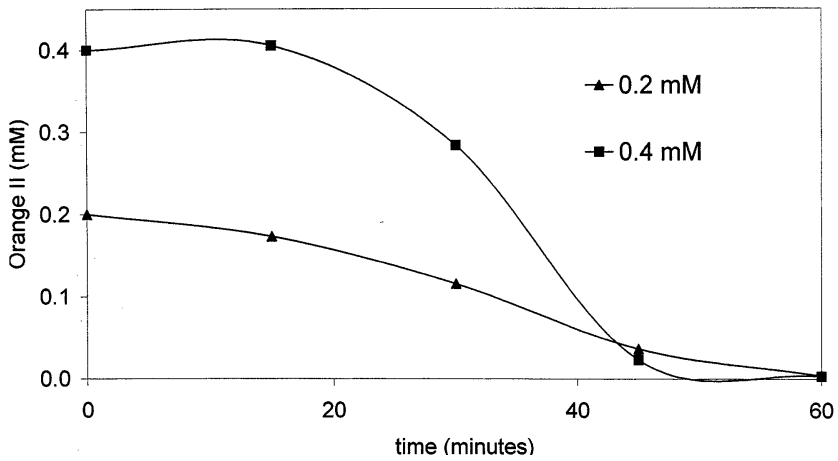

Figure 7. Kinetics of Orange II decoloration in solution at an initial pH 5.1 in the presence of $\mathrm{H}_{2} \mathrm{O}_{2}(10 \mathrm{mM})$ under Suntest light irradiation mediated by a C-Nafion/Fe-ion fabric.

Decoloration of Orange II by a C-Nafion/Fe-ion fabric. Figure 7 presents the degradation kinetics for two concentrations of Orange II under Suntest light irradiation in a cylindrical reactor stirred at a rate that avoids mass transfer problems despite the vigorous stirring employed. The shape of the curves in Figure 7 suggest lateral boundaries in the reactor vessel due to the C-Nafion/Fe-ion fabric having a small active zone. In this zone, the oxidative radicals are generated. The chemical reaction between Orange II and the oxidative radicals occurs under a turbulent flow regime in the reaction vessel.

Increase in the Biodegradability of Orange II During the Pretreatment on C-Nafion/Fe Fabrics. Figure 8a shows the $\mathrm{BOD}_{5}$ evolution of untreated and treated solutions of Orange II $(0.2 \mathrm{mM})$ showing the beneficial effect of the photocatalysis mediated by $\mathrm{C}-\mathrm{Nafion} / \mathrm{Fe}$-ion fabrics on the biodegradability of the solution. As shown in the lower part of Figure 8a, the initial Orange II solution is nonbiodegradable. But when Orange II is pretreated for 90 and $120 \mathrm{~min}$, the intermediates present a very high biodegradability. On smaller organic intermediates with a higher degree of oxidation, the bacterial action proceeds more favorably, as reported for other model compounds from our laboratory ${ }^{20,21}$ The photohydroxylation and photooxidation of the aromatic ring make the bacterial attack easier because the resonance energy of the ring has been lowered, and the bacteria benefits additionally from the energy released because of this bond breaking.

Figure $8 \mathrm{~b}$ shows the evolution of the $\mathrm{BOD}_{5} / \mathrm{COD}$ ratio as a function of pretreatment time. This ratio increases up to 0.35 and 0.76 after 90 and $120 \mathrm{~min}$ of pretreatment. As a reference, the parameter for biodegradable wastewaters is 0.4 . The insert in Figure $8 \mathrm{~b}$ shows the evolution of the average oxidation state (AOS) as a function of time. The AOS represents the oxidation
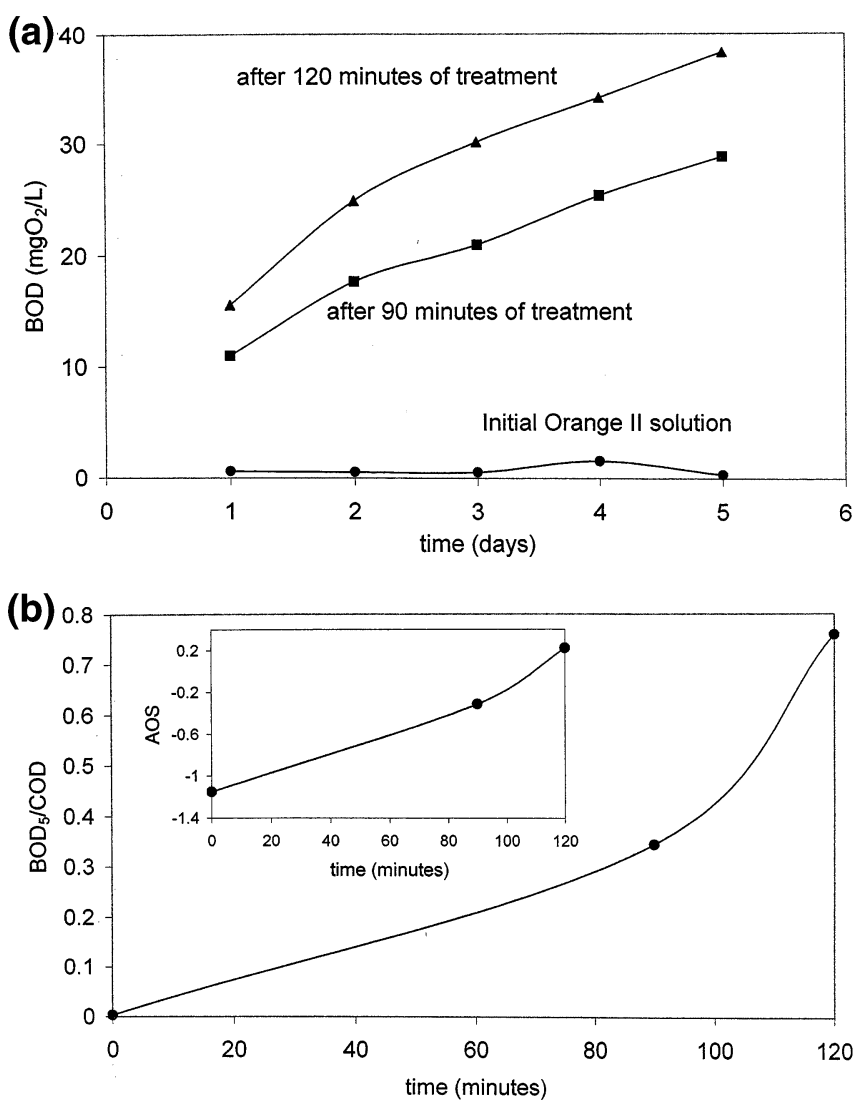

Figure 8. Biodegradation results (a) obtained for Orange II solutions after different pretreatment times on C-Nafion/Fe-ion fabrics and (b) increase in the biodegradability index of Orange II solutions as a function of pretreatment times on C-Nafion/Fe-ion fabrics. For other details see text. The insert shows the evolution of the AOS as a function of pretreatment times.

state of a solution as +4 for $\mathrm{CO}_{2}$ and -4 for $\mathrm{CH}_{4}{ }^{22}$ The insert in Figure $8 \mathrm{~b}$ indicates that with reaction time the intermediates of Orange II decomposition become more oxidized during the pretreatment.

Fourier-Transform Infrared Spectroscopy of C-Nafion/ Fe-ion Fabrics. Figure 9 shows the external reflection FTIR spectra of a C-Nafion/Fe-ion fabric after reaction with Orange II for different times. The spectrum of the "fresh" catalyst directly after preparation was used as reference. The observed positive bands at 1670 and $1640 \mathrm{~cm}^{-1}$ indicate the presence of surface carboxylate groups. ${ }^{23}$ The amount of these surface groups is the highest after 30 min (Figure 9b) of the Orange II photodecomposition reaction, whereas at the beginning and after $50 \mathrm{~min}$ of reaction, the surface densities of the carboxylate groups are very low. The broad negative absorbance band at around $1620 \mathrm{~cm}^{-1}$, clearly visible in Figure $9 \mathrm{a}, \mathrm{c}$, is assigned to water molecules surrounding iron ions in the Nafion structure. This water is replaced by the adsorbed decomposition products with carboxylic and probably aromatic groups during photodegradation of Orange II.

Figure 10 shows the reflection infrared spectra of the C-Nafion/Fe-ion fabric equilibrated with Orange II in dark after different conditioning times. The observed band at $1646 \mathrm{~cm}^{-1}$ suggests the presence of surface carboxylate groups. The amount of carboxylate groups increased with reaction time. The significant broadening of the band after $24 \mathrm{~h}$ indicates the formation of several surface products. ${ }^{25}$ The strong adsorption of these decomposition products may inhibit further catalytic reactivity of the catalyst. 


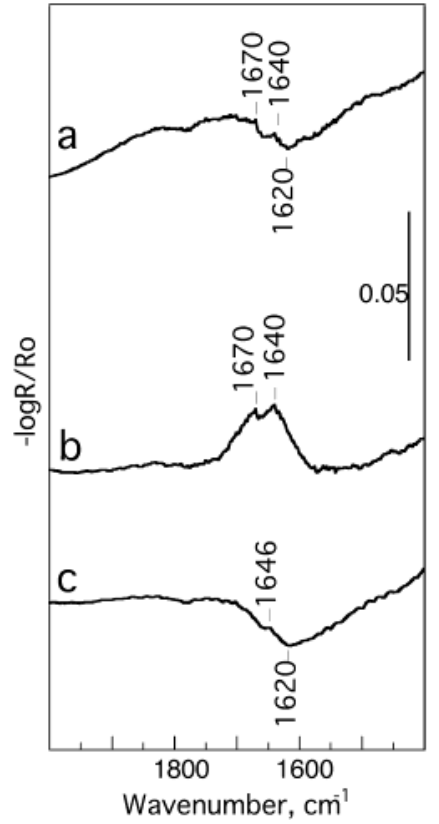

Figure 9. External reflection FTIR spectra of a C-Nafion/Fe-ion fabric during Suntest irradiation of Orange II $(0.2 \mathrm{mM})$ in the presence of $\mathrm{H}_{2} \mathrm{O}_{2}(10 \mathrm{mM})$ after (a) $15 \mathrm{~min}$, (b) $30 \mathrm{~min}$, and (c) 50 min reaction.

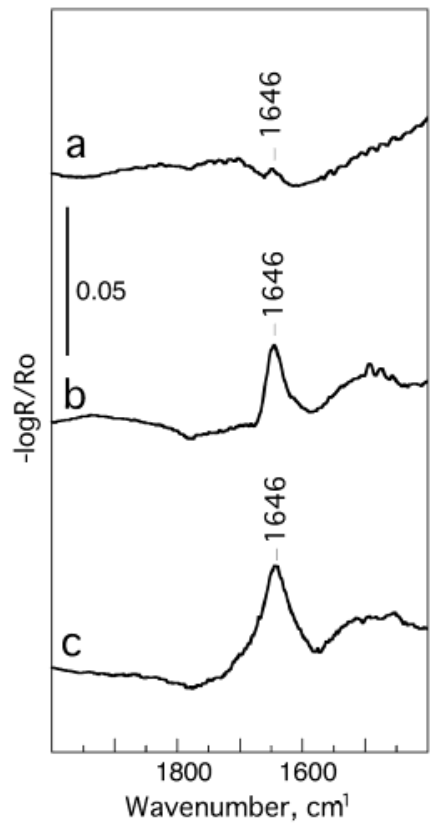

Figure 10. External reflection FTIR spectra of the C-Nafion/Fe-ion fabrics equilibrated with Orange II $(0.2 \mathrm{mM})$ in the dark at different times: (a) $1 \mathrm{~h}$; (b) $8 \mathrm{~h}$; (c) $24 \mathrm{~h}$.

Figure 11a shows the external reflection infrared spectra of the $\mathrm{C}$-Nafion/Fe-ion fabric after equilibration with different concentrations of oxalic acid. The spectrum of the C-Nafion/Feion fabric after preparation is our reference. Oxalic acid at 1 $\mathrm{mM}$ concentration forms a significant amount of complexes with iron present ${ }^{3}$ in the Nafion. This is indicated by the presence of two strong absorbance bands: a shoulder at $1688 \mathrm{~cm}^{-1}$ and a band at $1646 \mathrm{~cm}^{-1}$. With a higher oxalic acid concentration in solution above $5 \mathrm{mM}$, iron is removed from Nafion. The broad negative absorption bands at around $1620 \mathrm{~cm}^{-1}$, clearly visible in traces b and $c$ of Figure 11a, indicate removal of water molecules surrounding iron ions in the Nafion structure. This observation supports the conclusion about the strong leaching of iron from Nafion with a concentrated oxalate solution.
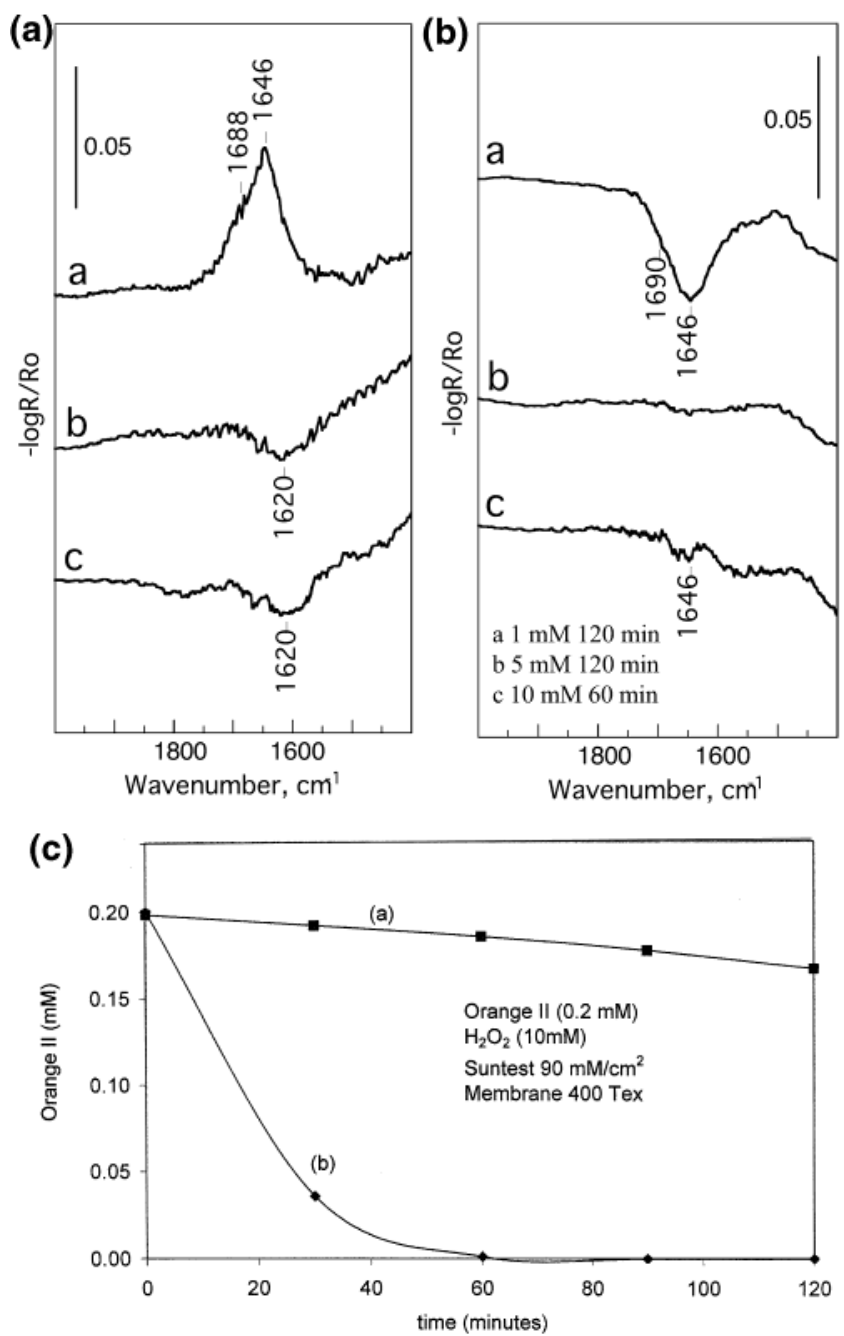

Figure 11. External reflection FTIR spectra of the C-Nafion/Fe-ion fabrics (a) equilibrated in the dark for $16 \mathrm{~h}$ with different concentrations of oxalic acid and (b) equilibrated in the dark with different concentrations of oxalic acid for $16 \mathrm{~h}$ and then reacted $2 \mathrm{~h}$ with Orange II $(0.2$ $\mathrm{mM})$ in the presence of $\mathrm{H}_{2} \mathrm{O}_{2}(10 \mathrm{mM})$ under Suntest irradiation: (a) oxalic acid $1 \mathrm{mM}$; (b) oxalic acid $5 \mathrm{mM}$; (c) oxalic acid $10 \mathrm{mM}$. Panel c shows results of the photodecomposition of Orange II mediated by two differently pretreated $\mathrm{C}-\mathrm{Nafion} / \mathrm{Fe}$-ion fabrics. For other details, see text.

Figure $11 \mathrm{~b}$ shows external reflection spectra of the C-Nafion/ $\mathrm{Fe}$-ion fabric after exposure to an oxalic acid solution for $16 \mathrm{~h}$ and then in reaction with Orange II. The spectra of the C-Nafion/ Fe-ion fabric after exposure to different oxalic acid solutions for $16 \mathrm{~h}$ were used as the references to see the effect of Orange II decomposition. At $1 \mathrm{mM}$ oxalate concentration and $2 \mathrm{~h}$ of irradiation of the Orange II solution (trace a, Figure 11b) the reflection spectrum shows two negative bands: a shoulder at 1690 and a strong band at $1646 \mathrm{~cm}^{-1}$. The band positions and intensities are almost identical to those presented in Figure 11a, but they are negative. This indicates the disappearance of the produced iron oxalate complex during exposure to $1 \mathrm{mM}$ oxalate solution after the photodegradation of Orange II. The C-Nafion/ Fe-ion fabric sample exposed to 5 and $10 \mathrm{mM}$ oxalate solution removed the majority of the iron from the Nafion, and therefore, oxalic acid was adsorbed in an almost negligible amount (traces $\mathrm{b}$ and c, Figure 11b). As a consequence, after Orange II photodecomposition for $2 \mathrm{~h}$, the catalyst shows only a very small removal of the carboxylate surface species.

Figure 11c shows the results for the photodegradation of Orange II under light in the presence of C-Nafion/Fe-ion fabrics 


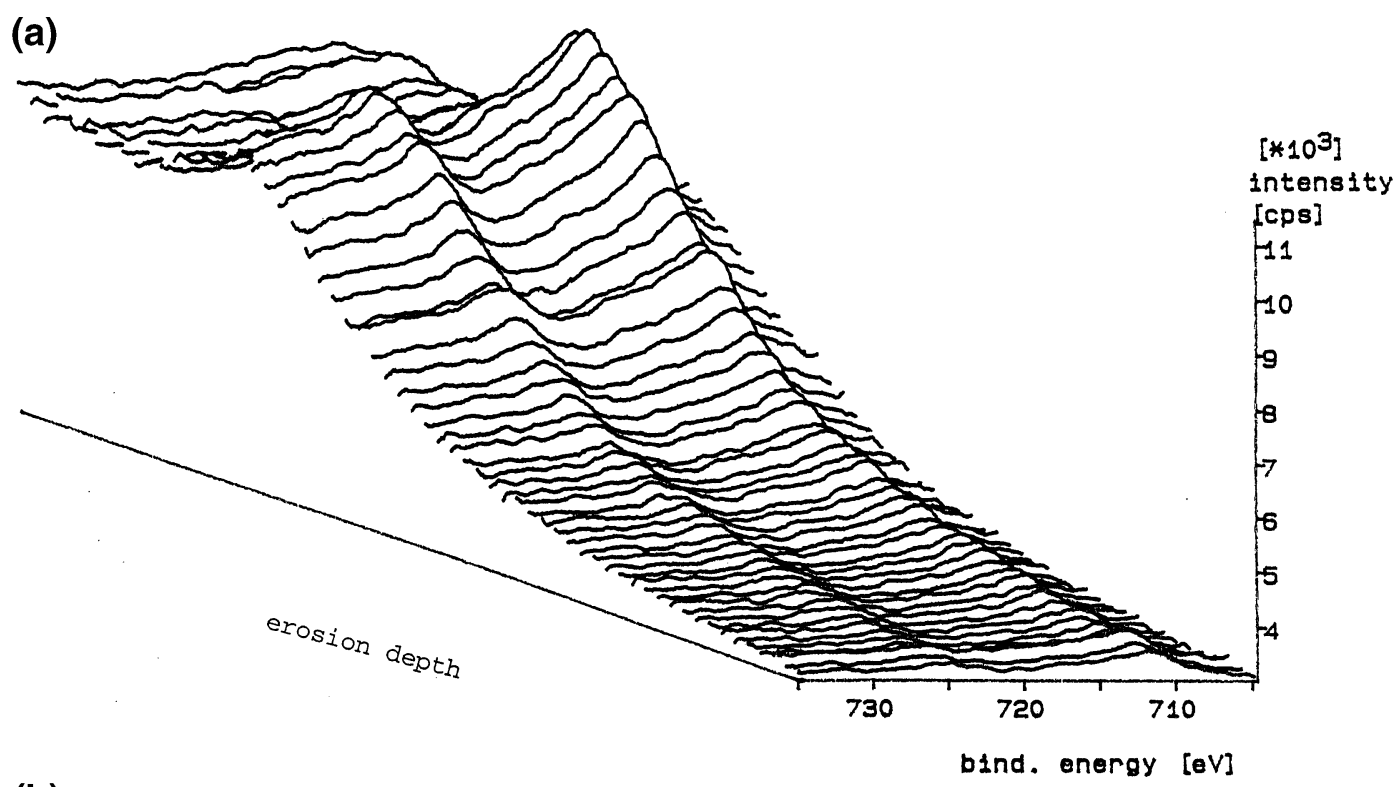

(b)
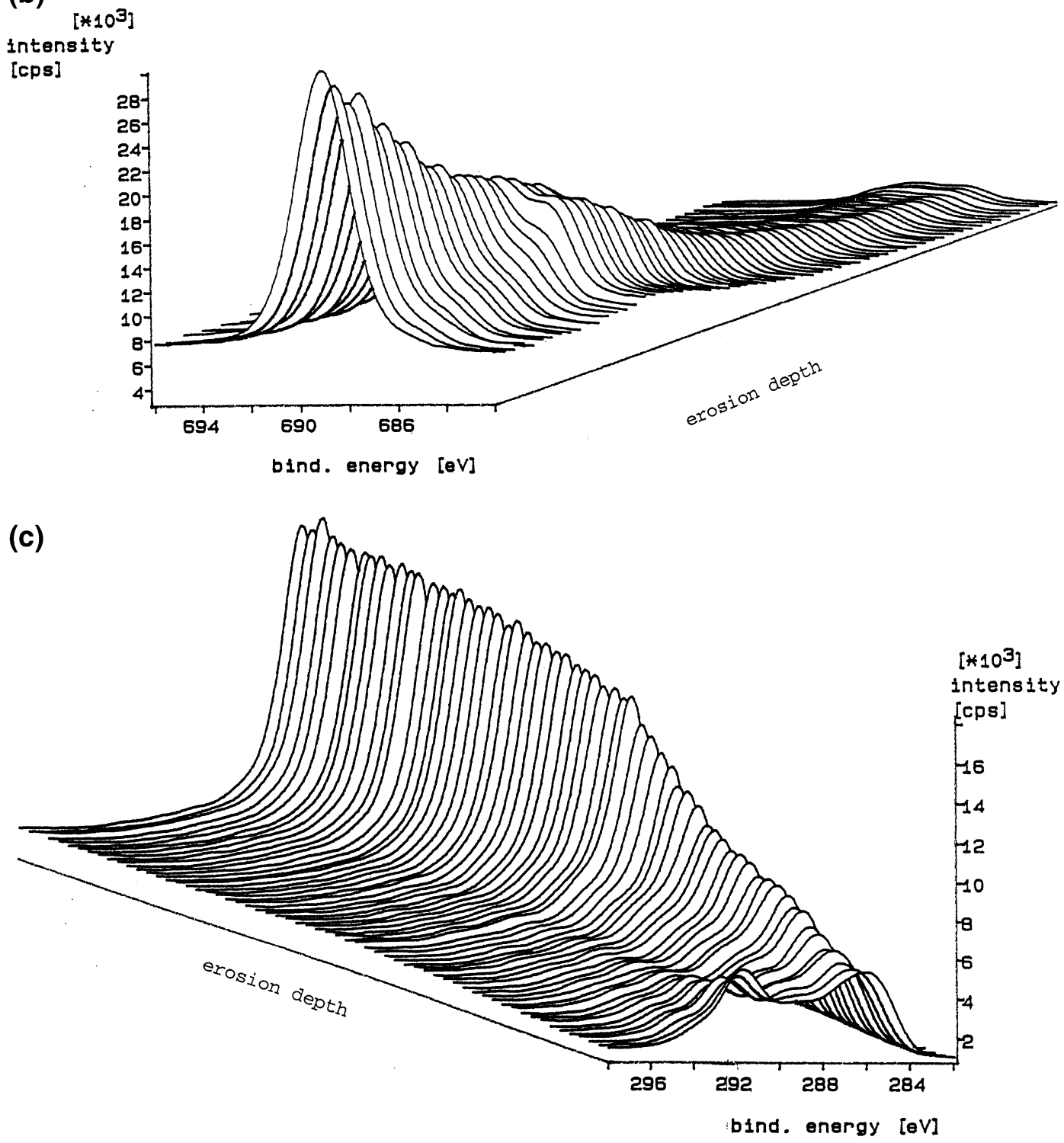

Figure 12. Fe species as a function of the erosion depth (a) during the Ar-ion sputtering of the C-Nafion/Fe-ion fabric surface, (b) concentration gradient of the different species of fluoro compounds as a function the erosion depth during Ar-ion sputtering of the $\mathrm{C}-\mathrm{Nafion} / \mathrm{Fe}$-ion fabric surface, and (c) Removal of the surface from $\mathrm{C}-\mathrm{F}$ groups of the C-Nafion/Fe-ion fabric surface with increasing erosion of the catalyst topmost layers until reaching the stable profile of the $\mathrm{C}$ concentration at a certain depth inside the C-Nafion fabric. 

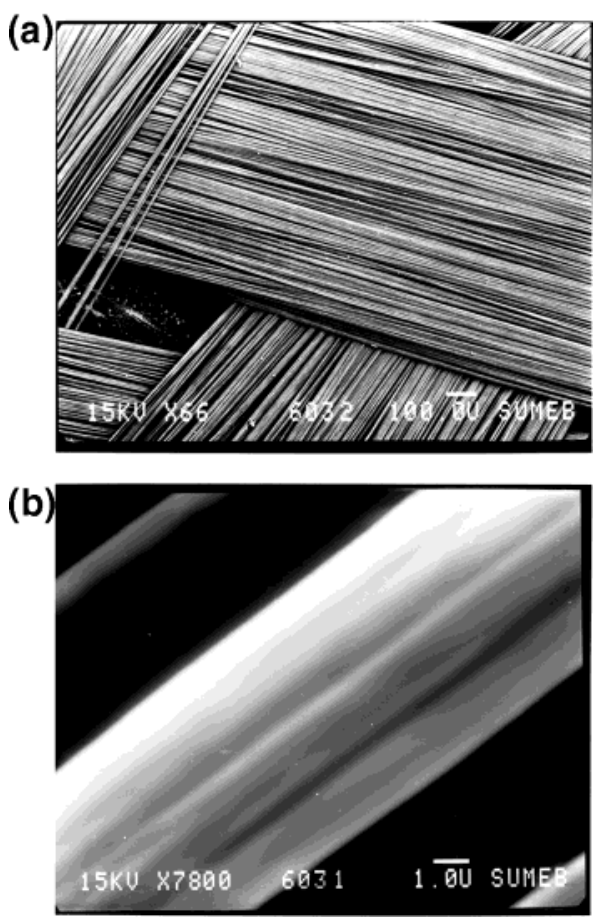

Figure 13. Scanning electron microscopy of (a) a C-woven fabric (400 Tex, each fiber is made up of 6000 filaments of $7 \mu \mathrm{m}$ diameter each) and (b) one filament $7 \mu \mathrm{m}$ in diameter making up the basic fibers used in the C-fabric (400 Tex).

that have been pretreated in two different ways. Trace a represents the photodegradation of Orange II solution on the C-Nafion/Fe-ion fabric that was pretreated in $10 \mathrm{mM}$ oxalic acid for $2 \mathrm{~h}$ and then was washed and used as a photocatalyst. Trace $b$ shows the photodegradation of the same Orange II solution but with a photocatalyst pretreated for 2 hours in a 1 $\mathrm{mM}$ oxalic acid solution. The latter pretreatment of the photocatalyst did not dissolve the Fe-ions from the Gierke cages of Nafion, and the Orange II decomposition preceded readily. The results presented in Figure 11c are entirely consistent with the results obtained by FTIR (Figure 11a,b) supporting the conclusion about significant reactivity of the C-Nafion/Fe-ion fabrics in solution under $5 \mathrm{mM}$ acetic acid.

Another important finding of the IR spectroscopy is that the main decomposition channel of Orange II on a C-Nafion/Feion fabric involves an $\mathrm{Fe}$-carboxylate redox photo-Kolbe process leading to the decarboxylation of the organic compound as mentioned previously in eq 3 .

X-ray Photoelectron Spectroscopy (XPS). No significant difference was observed in the oxidation state of the Fe present in the $\mathrm{C}$-Nafion/Fe-ion fabrics before and after photocatalytic decomposition of Orange II. A Gaussian-Lorentzian fitting of the XPS peaks was carried out by the Shirley-type background correction, subtracting the X-ray satellite peaks. ${ }^{16}$ Polynomial second-order fits of the experimental curves were directed toward the matching of the asymmetric shape of the corrected XPS signals referencing to the known binding energies: $\mathrm{Fe}$ metal $706.7 \mathrm{eV}$; $\mathrm{FeO} 709.6 \mathrm{eV} ; \mathrm{Fe}_{2} \mathrm{O}_{3} 710.9 \mathrm{eV} ; \mathrm{Fe}_{3} \mathrm{O}_{4} 711.4$ $\mathrm{eV}$. Sputtering of the $\mathrm{C}-\mathrm{Nafion} / \mathrm{Fe}$-ion fabrics was carried out with Ar and the XPS depth profile and was recorded on 3D profile graphical plots that are shown below.

Figure 12a presents the continuous 3D representation of the Fe surface concentration. It is clearly seen that the maximum Fe concentration is below the topmost layers (of $\sim 2 \AA$ each) shown for the $\mathrm{Fe} 2 \mathrm{p}_{3 / 2}$ doublet centered at $714.7 \mathrm{eV}$ in Figure 12a. The estimation of $2 \AA$ for each layer is an approximation. (a)

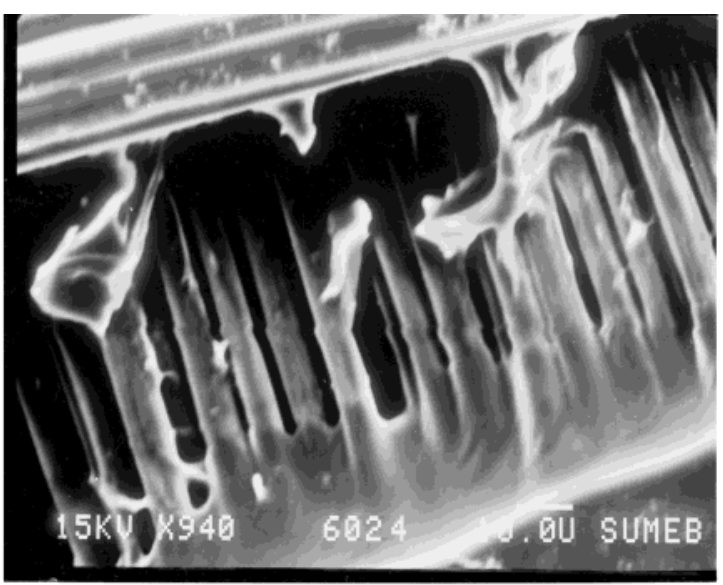

(b)

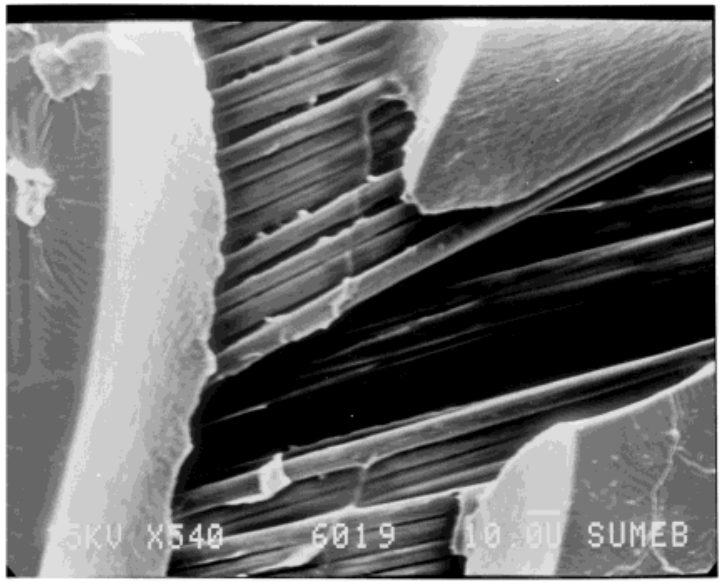

Figure 14. Scanning electron microscopy of (a) Nafion deposits on $\mathrm{C}$-filaments showing thin deposits attached to the surface of the C-fabric and (b) the Nafion attached to the C-filaments showing thick Nafion deposits upon the $\mathrm{C}$-fabric surface.

When erosion of the C-Nafion/Fe-ion fabric was carried out by sputtering with $\mathrm{Ar}^{+}$-ions, the layers of Nafion and of the $\mathrm{C}$-fibers were stripped at a different rate. This leads to a different stripping depth for Nafion and $\mathrm{C}$. The absence of Fe from the topmost layers is due to two factors: (a) the Fe-ions exchanging with the $\mathrm{H}^{+}$of sulfonic pending group inside the Gierke cages ${ }^{30}$ placing the Fe-ions at some distance from the topmost Nafion surface and (b) the selective shielding by $\mathrm{C}-\mathrm{F}$ groups of the $\mathrm{Fe}$ species in the interior of the Nafion Gierke cages.

Figure $12 \mathrm{~b}$ presents the concentration gradient of $\mathrm{F}$ (for the different varieties of fluoro compounds found on the fabric surface) showing that the Nafion F surface species decrease in the layers located further away from the fabric surface. This shows that the Nafion forms a good film on the C-fabric. Furthermore, a second shoulder appears as the erosion penetration depth increases revealing a second and different $\mathrm{C}-\mathrm{F}$ compound at some depth from the fabric surface.

The removal of the $\mathrm{C}-\mathrm{F}$ groups is seen to proceed with increased sputtering time leading to a zone where the $\mathrm{C}$-substrate concentration predominates. The number of layers removed in terms of the $\mathrm{C}-\mathrm{F}$ species in Figure $12 \mathrm{~b}$ matches the erosion zone for the $\mathrm{C}-\mathrm{F}$ species reported in Figure 12c. Figure 12c backs quantitatively the results presented in Figure $12 \mathrm{~b}$. The $\mathrm{C}-\mathrm{F}$ species is the main component of the Nafion polymer, and it is the decomposition of $\mathrm{H}_{2} \mathrm{O}_{2}$ over the Fe-ionic species in the Nafion cages that produces the oxidative radicals necessary for Orange II decomposition. ${ }^{3-6}$ Furthermore, experiments following the sulfur enrichment of the C-Nafion/Fe-ion fabrics show that the topmost layers removed by $\mathrm{Ar}^{+}$-ion 


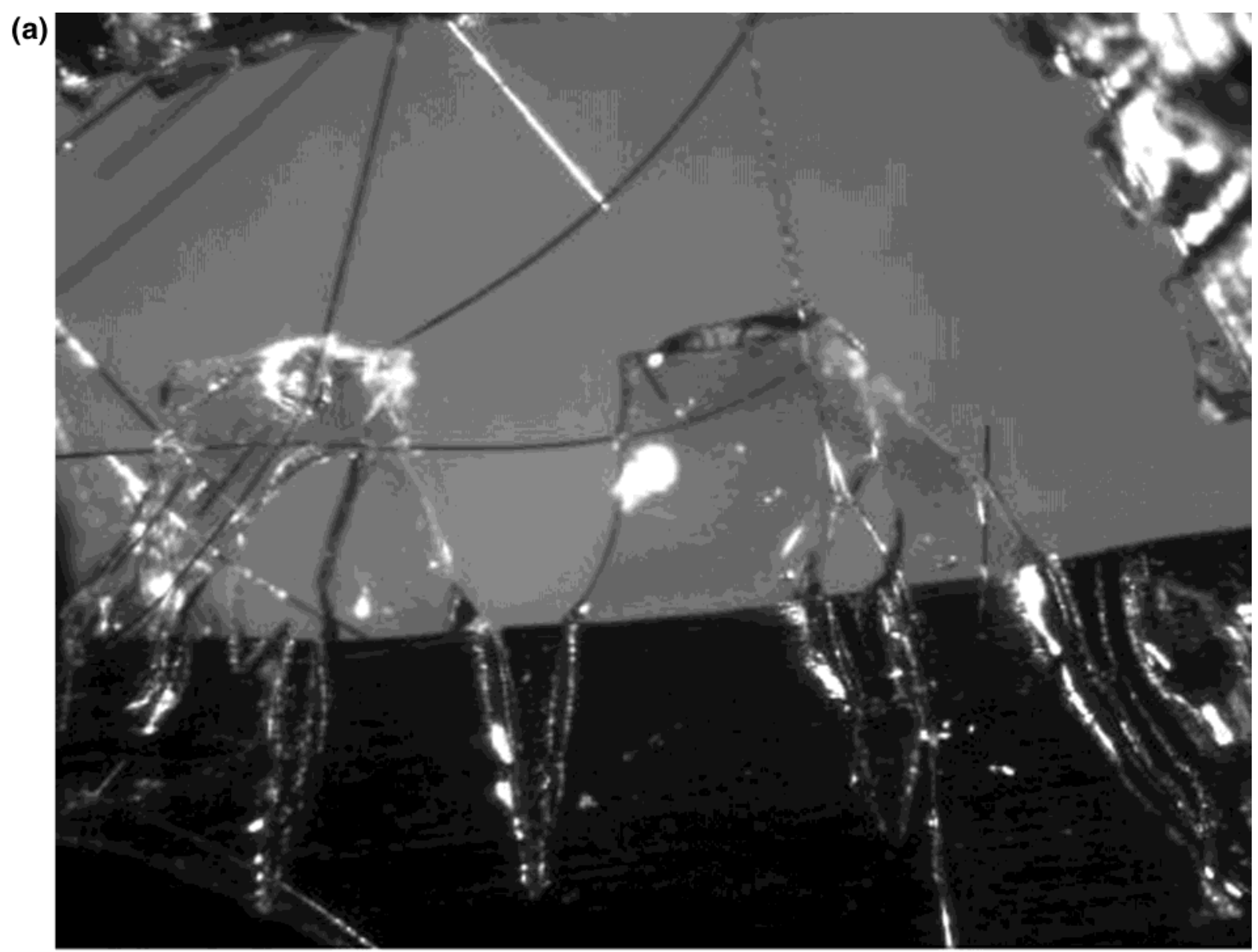

(b)

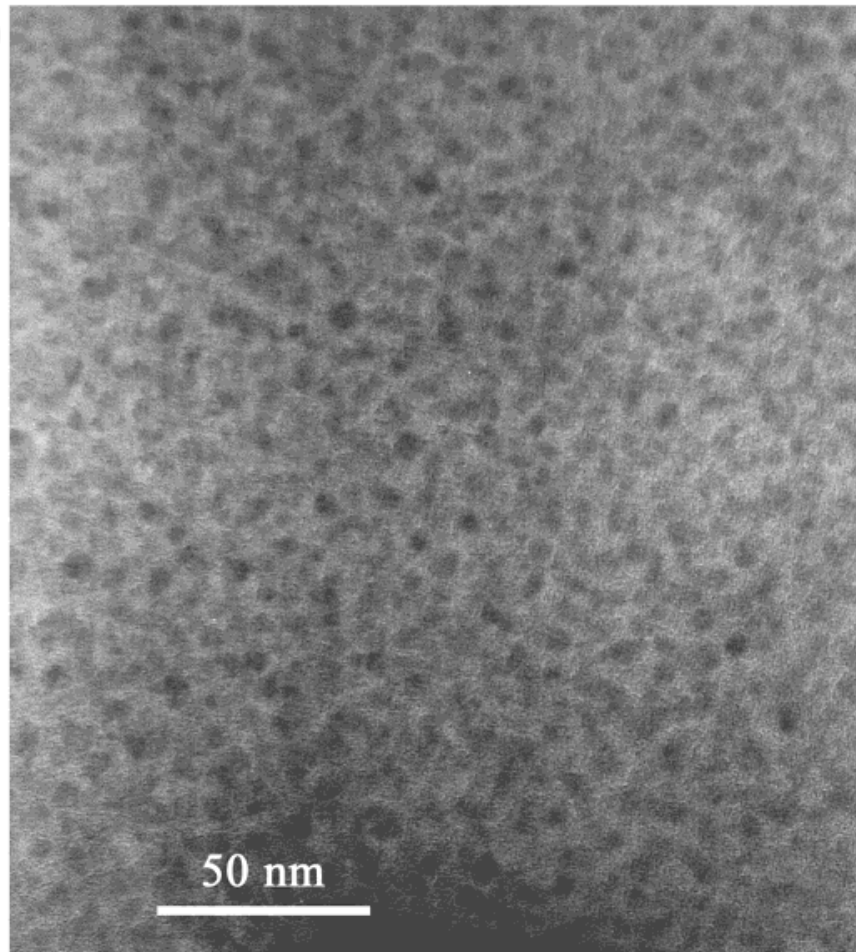

Figure 15. Optical microscopy (a) of the C-Nafion/Fe-ion fabric surface after Orange II photocatalytic decoloration and (b) transmission electron microscopy of the homogeneously dispersed Fe clusters on the C-Nafion/Fe-ion fabric surface before the photocatalytic runs on Orange II. A media size of $3.8 \mathrm{~nm}$ was accounted for from the histogram of the sizes of the Fe clusters on the $\mathrm{C}$ surface.

sputtering at $165 / 165 \mathrm{eV}$ are within the same distance from the surface as the $\mathrm{C}-\mathrm{F}$ layers observed for the Nafion sulfonate with a binding energy value (BE) of $1697 / 170 \mathrm{eV}$.
Microscopy Studies on the C-Fabrics and the Loaded C-Fabric. A detailed presentation of the uneven surface of the $\mathrm{C}$-fabric comprising the bundle of $\mathrm{C}$-fibers is presented by 
scanning electron microscopy (SEM) in Figure 13a and a single C-filament is shown in Figure 13b. The scale found in the lower right-hand in Figure 13b shows that each individual filament has a diameter of $7 \mu \mathrm{m}$. Orange II disappearance in the active zone near the $\mathrm{C}$-Nafion fabric where the oxidative radicals are generated by $\mathrm{H}_{2} \mathrm{O}_{2}$ on the $\mathrm{Fe}$ clusters was optimized and proceeds in $40 \mathrm{~min}$ (Figure 1). The voids in the $\mathrm{C}$-fabric structure would not be beneficial with regard to a regular and continuous generation of oxidative radicals on the $\mathrm{C}$-fabric in the presence of $\mathrm{H}_{2} \mathrm{O}_{2}$.

During the dip coating deposition of Nafion onto the C-fabric, it reveals submicron and micron Nafion deposits as shown in Figure 14a,b by scanning electron microscopy. Submicron-sized thin Nafion deposits were observed on the 400 Tex C-fabric and on the C-filaments covering a large section surface area. This is shown in Figure 14a. Thicker Nafion deposits of 20$30 \mu \mathrm{m}$ were also observed along with the former ones covering $10-20 \%$ of the C-fabric and C-filaments as shown in Figure $14 \mathrm{~b}$.

Figure $15 \mathrm{a}$ presents the $\mathrm{C}-\mathrm{Nafion} / \mathrm{Fe}$-ion fabric with the detailed Nafion deposits protruding out of the surface of the C-filament. The Nafion deposits containing the Fe-ions stay on the $\mathrm{C}$-filaments after several cycles even up to runs at $\mathrm{pH} 10$. The surface of the C-filaments was still covered with thin Nafion submicron deposits revealing the improved stability of the $\mathrm{C}-\mathrm{Nafion} / \mathrm{Fe}$-ion fabrics with respect to the glass-Nafion/Fe fibers previously reported by our laboratory. ${ }^{4}$

Figure 15b shows the Fe clusters deposited on the C-fabric as observed by TEM. The highly dispersed dark spots reveal a very good distribution for $\sim 200$ clusters measured. A median size of $\sim 3.8 \mathrm{~nm}$ was obtained for the Fe particles encapsulated in the Gierke cages before and after their use. The clusters varied between 3.5 and $4.3 \mathrm{~nm}$. These values lie in the limits of the spacing $(d)$ between $3.46 \leq d \leq 4.66 \mathrm{~nm}$ reported for the Nafion Gierke cages by small-angle X-ray diffraction. ${ }^{26}$ Because the entrances of the Gierke cages have a dimension of $\sim 1 \mathrm{~nm}$, the Orange II molecules having a size larger than the aperture will be decomposed in solution by the oxidative radicals formed on the Fe clusters (Figure 15b) formed inside the Nafion cages. It is therefore crucial to prepare thinner Nafion films on the C-filaments to minimize the path followed by the oxidative radicals needed to oxidize Orange II. Work in this direction is in progress and will be reported elsewhere at a later date.

\section{Conclusions}

This work presents the first report on C-Nafion/Fe-ion fabrics that work as active supported photocatalysts in Fenton immobilized reactions. The optimization of the decomposition of Orange II taken as a model compound has been worked out in detail. The mechanism of the decoloration of azo dye was backed by experimental evidence obtained by infrared spectroscopy showing the formation and disappearance of the carboxylates intervening in the photocatlytic process. From the result obtained by FTIR spectroscopy, the decomposition channel of Orange II on the $\mathrm{C}$-Nafion/Fe-ion fabric involves an $\mathrm{Fe}$-carboxylate redox photo-Kolbe reaction. A detailed characterization of the surface parameters of the C-Nafion/Feion fabric has been worked out through XPS, SEM, TEM, and BET techniques. A remarkable increase of the Orange II biodegradability was observed after the Fenton immobilized photoassisted pretreatment.

Acknowledgment. We thank E. Bere (SIMIS Poitiers University) and E. Gautron (SME-Poitiers University) for their help with the scanning and the transmission electron microscopy. This work was funded by CTI TOP NANO-21 under Grant No. 6116.4 (Bern, Switzerland). We thank M. Picasso of the Department of Applied Mathematics, Swiss Federal Institute of Technology, for his help during this study.

\section{References and Notes}

(1) Ollis, F. D.; Al-Ekabi, H. Photocatalytic Purification and Treatment of Water and Air; Elsevier: Amsterdam, 1993.

(2) Fernandez, J.; Bandara, J.; Lopez, A.; Kiwi, J. Langmuir 1999, $15,185$.

(3) Bozzi, A.; Yuranova, T.; Mielczarski, J.; Kiwi, J. Chem. Commun. 2002, 2202.

(4) Dhananjeyan, M.; Kiwi, J.; Albers, P.; Enea, O. Helv. Chim. Acta 2001, 84, 3433

(5) Dhananjeyan, M.; Mielczarski, E.; Thampi, K.; Bensimon, M.; Kiwi, J. J. Phys. Chem. B. 2001, 105, 12046.

(6) Fernandez, J.; Dhananjeyan, M.; Kiwi, J.; Senuma, Y.; Hilborn, J. J. Phys. Chem. B. 2000, 104, 5298 and references therein.

(7) Mochida, I.; Kawano, S.; Hironaka, M.; Kawabuchi, Y.; Korai, Y.; Matsumura, Y.; Yoshikawa, M. Langmuir 1997, 13, 5316.

(8) Bulushev, D.; Minsker-Kiwi, L.; Yuranov, I.; Sururova, E.; Buffat, Ph.; Renken. A. Y. J. Catal. 2002, 210, 149.

(9) Harrick, N. J. Internal Reflection Spectroscopy; Harrick Scientific: Ossining, NY, 1987.

(10) Shirley, A. Phys. Rev. 1979, B5, 4709.

(11) DIN Norms N39; National Physics Laboratory: Teddington, U.K. 1982.

(12) Bandara, J.; Herrera, F.; Kiwi, J. J. Chem. Res. 1998, 234. Kiwi, J.; Denisov, N.; Gak, Y.; Ovanesyan, N.; Buffat, P.; Suvorova, E.; Gostev, F.; Titov, A.; Sarkisov, O.; Albers, P.; Nadtochenko, P. Langmuir 2002, 18,9054 .

(13) Nadtochenko, V.; Kiwi, J. Chem. Soc., Faraday Trans. 1997, 93, 2373

(14) Herrera, F.; Pulgarin, C.; Nadtochenko, V.; Kiwi, J. Appl. Catal. B. 1998, 17, 141 .

(15) Safarzade-Amiri, A.; Bolton, J.; Cater, S. J. Adv. Oxid. Technol. 1996, 1,18 .

(16) Halmann, M. Photodegradation of Water Pollutants; CRC Press: Boca Raton, FL, 1996.

(17) Ruppert, G.; Bauer, G.; Heisler, G. J. Photochem. Photobiol., A 1993, 73,75

(18) Nadtochenko, V.; Kiwi, J. Inorg. Chem. 1998, 37, 5233.

(19) Bandara, J.; Kiwi, J. New J. Chem. 1999, 23, 37.

(20) Kiwi, J.; Pulgarin, C.; Peringer, P. New J. Chem. 1993, 17, 487.

(21) Parra, S.; Malato, S.; Pulgarin, C. Appl. Catal. B 2002, 36, 131.

(22) Scott, J.; Ollis, F. D. Environ. Prog. 1995, 14, 88.

(23) Mehrotra, R.; Bohra, R. Metal Carboxylates; Academic Press: London, 1983

(24) Harmer, M.; Farneth, W.; Sun, Q. J. Am. Chem. Soc. 1996, 118, 7708 .

(25) Boehm, H.-P.; Knözinger, H. In Catalysis: Science and Technology; Anderson, R. J., Boudart, M., Eds.; Springer-Verlag: Berlin, 1983; Vol. 4 Chapter 2, p 40

(26) Gierke, D.; Munn, G.; Wilson, C. J. Polym. Sci. 1981, 19, 1687. 